\title{
Kursi Betawi: Bentuk Dan Fungsi Dalam Seni Pertunjukan
}

\author{
Gerry Rachmat \\ Institut Seni Budaya Indonesia (ISBI) Bandung \\ Jalan Buah Batu No. 212 Bandung
}

\begin{abstract}
Chair as one of supporting elements in the life of social society Indonesian in general. With progress in experiencing shift shape and function in accordance with the development of science, technology and art. The Chair became one of an important property on Betawi arts performances. The form of a Betawi Chair having a distinctive feature different from other chairs. A method of this research is through Participatory Action Research (PAR), by selecting Betawi Chair as the objects which used as a stage property in Lenong Betawi shaw in a television program. This Study producet an understanding of the concept of performances on thematic stage setting, and player'acts ( interaction of the players, stage and properties ) so giving atmosphere impression and the misit which is representatif and harmony.
\end{abstract}

Keywords: betawi chair, form, function, performance art

\begin{abstract}
ABSTRAK
Kursi sebagai salah satu elemen pendukung dalam kehidupan sosial masyarakat Indonesia pada umumnya. Dalam perkembangannya mengalami pergeseran bentuk dan fungsi sesuai dengan perkembangan ilmu pengetahuan, teknologi dan seni. Kursi menjadi salah satu properti yang penting pada pertunjukan kesenian Betawi. Bentuk dari Kursi Betawi memiliki ciri khas yang berbeda dari kursi yang lain. Metode penelitian ini yaitu melalui Participatory Action Research (PAR), dengan memilih Kursi Betawi sebagai objek yang dipergunakan sebagai properti panggung pertunjukan Lenong Betawi di suatu acara televisi. Kajian tulisan ini menghasilkan sebuah pemahaman konsep pertunjukan dengan penata panggung yangsesuai dengan tema, dan aktivitas pemain (interaksi pemain, panggung dan propertinya) sehingga memberikan suasana, kesan dan pesan yang representatif dan harmoni.
\end{abstract}

Kata kunci: kursi betawi, bentuk, fungsi, seni pertunjukana 


\section{PENDAHULUAN}

Kursi adalah sebuah perabotan yang biasa digunakan untuk duduk. Pada umumnya kursi memiliki 4 kaki untuk menopang beban dan keseimbanganya. Beberapa jenis kursi, seperti barstool (kursi bar), hanya memiliki 1 kaki di tengah. Kursi memiliki sandaran kaki.

Dalam kehidupan sosial, semua manusia pasti membutuhkan apa yang disebut dengan 'Kursi'. Mulai anak-anak, remaja, dewasa dan lansia semua membutuhkan kursi dalam aktivitas sehari-harinya. Bagi anak-anak, kursi dipakai untuk latihan bersosialisasi dengan teman, untuk naik sepeda bersama kakak dan orang tua, untuk belajar di kelas, mulai Play Group, TK, SD dan seterusnya. Bagi Remaja, kursi dipakai untuk belajar di kelas, duduk-duduk santai bersama teman dan keluarga. Bagi orang dewasa,kursi dipakai untuk bersantai dengan keluarga, untuk duduk bersama tamu, untuk makan bersama dengan keluarga dan masih banyak lagi. Sedang bagi lansia, kursi dipakai untuk santai, tempat duduk bagi yang sedang sakit dan lain-lain.

Dari beberapa jenis kursi tersebut di atas, dapat dikategorikan menjadi beberapa macam kursi, antara lain kursi anak, kursi sekolah/kuliah, kursi roda, kursi tamu, kursi temanten (pengantin), kursi bergoyang, kursi pengadilan, kursi makan, kursi pengawas ujian dan masih banyak yang lain. Dengan demikian, maka perlu untuk memahami bentuk dan fungsi kursi dalam kehidupan sosial ini.

Kebiasaan duduk di kursi bukanlah kebiasaan masyarakat Indonesia pada khususnya, duduk di kursi lebih dikenal oleh bangsa-bangsa Eropa yang lebih dahulu mengenyam kemerdekaan \& kemajuan dalam segala hal. Kursi masuk ke Indonesia pada abad ke-16, yaitu pada saat Bangsa Portugis merapat di pelabuhan kepulauan Indonesia (Gerry Rachmat, 2005: 80). Duduk bagi masyarakat Indonesia pada zaman dulu bertempat di atas batu alam, pada pijakan tangga pintu masuk rumah, bale-bale (berupa panggung kecil dari bahan bambu), pada potonganbatang pohon, pada tunggul bekas potongan pohon besar. Dari beberapa jenis aktivitas duduk dan tempat atau benda yang diduduki, maka dikelompokan dalam dua kelompok, yaitu fasilitas duduk \& tempat duduk. Fasilitas duduk contohnya, seperti batu alam, anak tangga, batang pohon, tunggul pohon. Sedangkan tempat duduk seperti:kursi, balebale, sofa, ayunan, pouf (sejenis kursi untuk meja rias), bench (sejenis sofa untuk berbaring ala putri raja).

Pembahasan bentuk dan fungsi ini yang berkaitan erat dengan bahasan utama, yaitu kursi yang berfungsi sebagai salah satu properti pendukung dari pertujukan berlatar budaya tradisi Betawi. Pemilihan kursi Betawi sebagai objek sampel pembahasan ini, karena bentuk dan fungsi yang khas dari masyarakat Betawi yang telah ada dan lestari sejak zaman penjajahan Belanda. Penulisan ini bertujuan untuk memberikan pemahaman mengenai Kursi Betawi dalam upaya meningkatkan apresiasi terhadap fungsi lain kaitannya dengan seni pertunjukan. Tujuan yang lain adalah memberikan wawasan atau ide-ide baru mengenai kemungkinan-kemungkinan aplikasi kursi lain sebagaiproperti pendukung pementasan Lenong Betawi.

\section{METODE}

Penelitian ini lebih mengutamakan bagian-bagian bentuk Kursi Betawi hingga peletakan atau set yang menyangkut simbol seperti strata sosial dari masyarakat Betawi. Kajian ini menggunakan pendekatan Participatory Action Research (PAR), dengan langkah-langkah yang dilakukan dimulai menyaksikankomunitas seni pertunjukan di lapangan, mendekati kontak atau membangun komunikasi strategis dengan objek- 
khususnya dengan group Lenong Betawi (pengisi acara Televisi), pengumpulan data (observasi langsung dan wawancara), membuat legal opinion atau analisa kasus, dan evaluasi data (Komis dan Robin Mc. Taggart dalam Denzin dan Lincoln, 2009: 438).

\section{HASIL DAN PEMBAHASAN}

Seiring dengan perkembangan zaman, seiring pula dengan terjadinya pergeseran atau perubahan bentuk dan fungsi Kursi Betawi tersebut. Hal ini dikarenakan adanya tuntutan untuk menyesuaikan dengan kebutuhan zaman, dengan tanpa meninggalkan budaya yang telah ada.

Dalam perkembangannya, kursi Betawi juga mengalami pergeseran makna dan fungsinya, tidak hanya pada ranah fungsi pragmatis melainkan fungsi dan makna simbolik. Makna kekuasaan dalam pemerintahan dapat disimbolkan dengan kursi, pada era kerajaan yang dipimpin oleh seorang raja, ratu, sultan, kursi atau yang lebih sering disebut singgasana mewakili tingginya pangkat serta kekuasaan seseorang.

Berdasarkan bentuk dan kegunaannya, singhasana dapat dibedakan menjadi dua, yaitu:

- Singhasana, tempat duduk khusus yang digunakan raja dalam ruang utama keraton, berbentuk seperti bangku yang mempunyai sandaran tangan dan sandaran punggung tinggi serta banyak terdapat ornamen hias.

- Dampar, singhasana tanpa alas tangan dan tanpa sandaran, yang selalu dibawabawa mengikuti kepergian raja apabila raja keluar dari ruang utama keraton (Gery Rachmat, 2005:54).

Dapat dipahami bahwa bentuk disampaikan di atas, yaitu seperti bentuk yang menonjolkan kekuatan sangat jelas terlihat dalam desain.

\section{Struktur Kursi}

Berdasarkan strukturnya, kursi terdiri dari bagian-bagiannya seperti: kaki, sandar- an punggung, sandaran tangan, dan alas duduk seperti pada (Gambar 2).

- Kaki Kursi, merupakan bagian kursi yang berada di bagian paling bawah bersentuhan langsung dengan alas untuk menempatkan kursi yang berfungsi untuk menyangga tempat dudukan, sandaran punggung dan sandaran tangan. Bentuk kaki kursi cukup beragam biasanya berupa batang-batang kayu dengan jumlah yang tidak menentu.

- Sandaran Punggung, merupakan bagian kursi yang terletak di bagian belakang dan diatas kaki kursi, fungsinya untuk menyangga tubuh orang yang sedang duduk agar tidak lelah karena dapat bersandar. Tidak ada ukuran pasti/standarisasi mengenai tinggi rendah ataupun lebarnya.

- Sandaran Tangan, merupakan bagian untuk menyandarkan tangan agar pemakai terkesan rileks. Tidak semua kursi mempunyai bagian ini, sehingga kehadirannya menyesuaikan dengan kebutuhan. Meskipun ada sandaran tangannya, namun orientasinya tidak semata untuk sandaran tangan, tetapi kadang juga untuk pertimbangan estetis sehingga kehadirannya tidak memberikan kenyamanan sesuai dengan fungsinya.

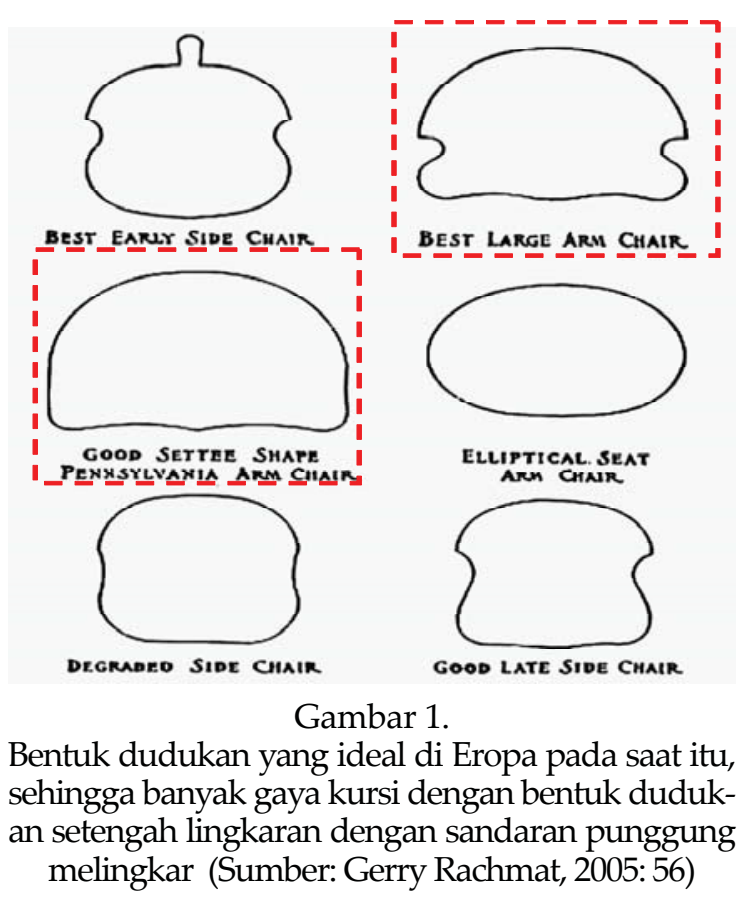




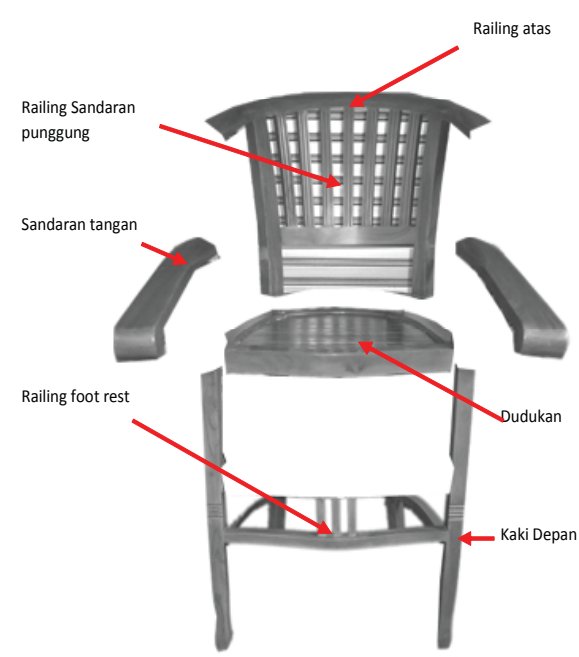

Gambar 2

Bagian-bagian pada Kursi

(Sumber: Dokumentasi Penulis, 2005)

- Alas Duduk, merupakan tempat untuk menempatkan pantat pengguna agar memberikan kenyamanan. Material yang digunakan dapat berupa papan kayu ataupun busa. Bentuk dudukan pantat dapat bersudut ataupun tanpa sudut, menyesuaikan dengan bentuk bagian-bagian yang lainnya. Ukuran ketinggianya menyesuaikan ketinggian pemakainya, karena untuk orang Indonesia akan berbeda dengan orang Eropa (Gery Rachmat, 2005: 55-57).

Dari aspek bentuk, kursi Betawi memiliki bentuk yang khas, dari masa ke masa yaitu lengkungan pada sandaran menyerupai pagar, yang membedakan hanya material, finishing, juga bentuk railing. Tetapi bentuk dasarnya sama dengan sandaran punggung yang menyatu dengan sandaran tangan melingkar merendah ke arah depan. Kursi Betawi memiliki banyak gaya dari bangsa Eropa juga Cina yang datang ke Indonesia, sehingga bentuk kursi Betawi pun semakin beragam.

Dilihat dari beberapa bentuk kursi Betawi tersebut, semuanya memiliki sandaran berbentuk setengah lingkaran yang melingkar merendah kearah depan menyatu menjadi sandaran tangan. Bentuk kaki ada yang melengkung, ada juga yang lurus, bentuk

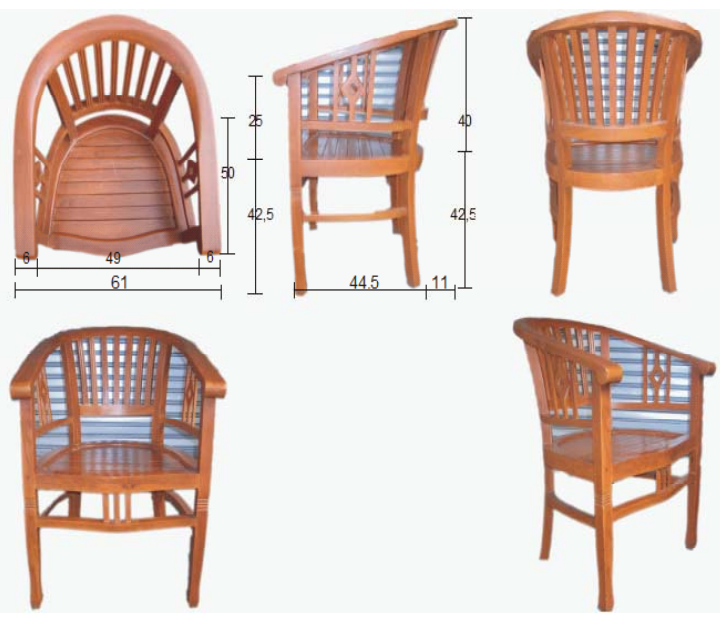

Gambar 3

Bagian-bagian pada Kursi Betawi modifikasi (Sumber: Dokumentasi Penulis, 2005)

tersebut mengindikasikan gaya yang hadir pada masa kursi tersebut dibuat. Hal tersebut membuktikan bahwa datangnya budaya dari bangsa asing akan menambah keragaman bentuk dan gaya pada kursi Betawi. Sama dengan kursi lain pada umumnya, kursi Betawi pun memiliki aspek/bagian yang menjadi kesatuan secara keseluruhan.

Visualisasi gaya kompeni mencerminkan adanya pengaruh dari Eropa pada bentuk kaki kursi, dan Cina pada lengkung pembatas bidang, terutama pada sandaran kursi. Percampuran gaya disebabkan pada abad ke-17 hingga abad ke-18, di Eropa timbul perhatian atau kesenangan pada seni Timur. Unsur hias yang disenangi terutama berasal dari kebudayaan atau kesenian Cina. Perkembangan gaya campuran ini mencapai puncaknya di Inggris pada masa pemerintahan Queen Anne, tahun 1702-1714, sehingga gaya tersebut disebut gaya Queen Anne (Gloag, 1977:417).

Salah satu contohnya adalah bentuk kaki yang melebar seperti gaya Queen Anne. Ini menandakan bahwa pada masa itu gaya Queen Anne sudah menjadi mode di zamannya, sehingga pengadopsian yang disesuaikan dengan kebutuhan akan memperkaya ragam bentuk kursi Betawi. 


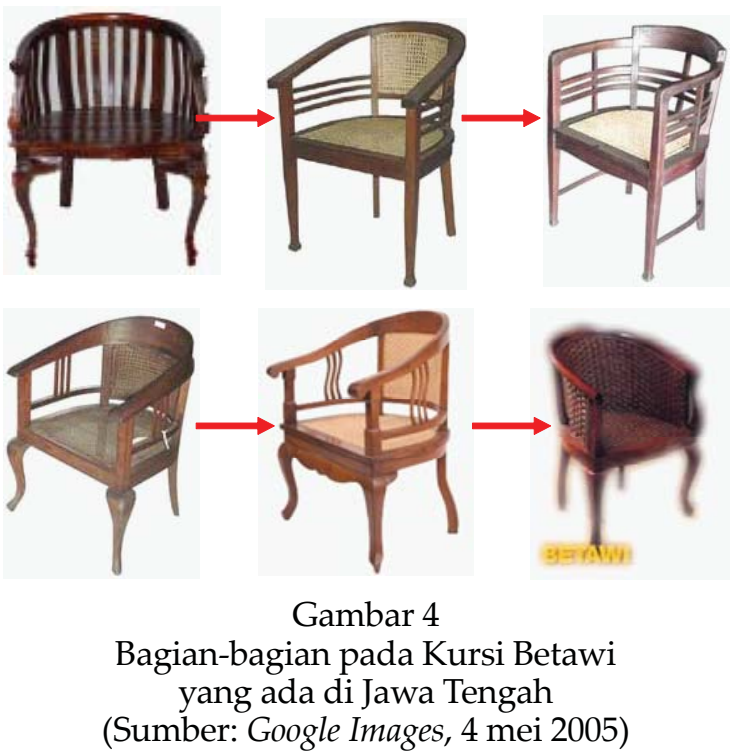

Analisis objek penelitian ini, ditetapkan menjadi 3 buah kursi dari 3 jenis umum Kursi Betawi yang dikenal oleh masyarakat Betawi yaitu: Lenong Rotan Betawi, Lenong Blok Jari, dan Sedanan Betawi. Analisis dari aspek-aspek kursi secara umum, struktur, konstruksi, bahan, ukuran, finishing, gaya, dan sumber inspirasi etnik daerah yang terkandung pada Kursi Betawi.

\section{Properti dalam Tata Panggung}

Sebagai media visual yang berupaya menghadirkan latar atau setting tempat dimana adegan berlangsung, Artistik panggung berupa setting atau dekorasi ditempatkan untuk menghidupkan suasana dan peristiwa bagi proses dramatik pada sebuah lakon. Artistik panggung yang tepat adalah ketika set keseluruhan panggung dapat menciptakan ruangan dan atmosfir yang sesuai dengan ide atau konsep garapan pementasannya. Oleh karena itu, seorang penata panggung harus mengetahui detil konsep yang diinginkan sutradaranya hingga apa yang ada dalam bayangan sutradara secara bentuk dapat divisualisasikan dan menjadi daya stimulus pula bagi pemain untuk memperkuat perannya.

Artistik panggung memperhitungkan

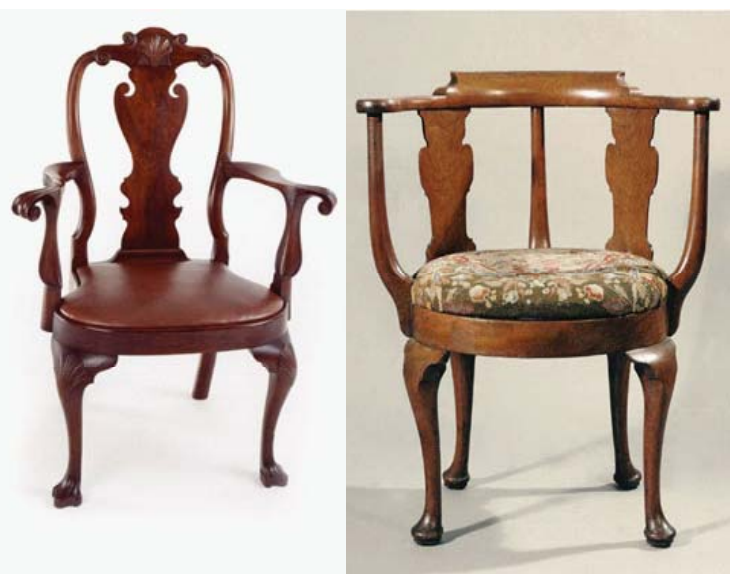

Gambar 5

Queen Anne Chair

(Sumber: Google Images, 4 Mei 2005)

juga bagaimana jarak pandang penonton sebagai penikmat agar keseluruhan pengadegan dapat dilihat secara utuh, maka pertimbangan beberapa hal tentang komposisi panggung harus diperhitungkan terlebih dahulu oleh seorang penata panggung, yaitu mengenai fungsi tata panggung.

\section{Fungsi Properti dalam Tata Panggung}

Dalam perancangantata panggung selain mempertimbangkan jenis panggung yang akan digunakan ada beberapa elemen komposisi yang perlu diperhatikan, di antaranya merencanakan gambar dekor dan properti. Penata panggung juga bertanggungjawab terhadap segala perabot yang digunakan. Karena keseluruhan objek yang ada di atas panggung dan digunakan oleh aktor membentuk satu lukisan secara menyeluruh. Perabot dan piranti sangat penting dalam mencipta lukisan panggung, terutama pada panggung arena di mana lukisan dekor atau bentuk bangunan vertikal tertutup seperti dinding atau kamar (karena akan menghalangi pandangan sebagian penonton) tidak memungkinkan diletakkan di atas panggung. Tata perabot kemudian menjadi unsur pokok pada tata panggung arena.

Unsur-unsur ini ditata sedemikian rupa 
sehingga bisa memberikan gambaran lengkap yang berfungsi untuk menjelaskan suasana dan semangat lakon, periode sejarah lakon, lokasi kejadian, status dan karakter peran, serta musim dalam tahun dimana lakon dilangsungkan ${ }^{1}$.

\section{Fungsi Kursi Betawi dalam Pertunjukan Lenong Betawi}

Lenong berkembang sejak akhir abad ke-19 atau awal abad ke-20. Kesenian teatrikal tersebut merupakan adaptasi dari masyarakat Betawi atas kesenian serupa seperti "komedi bangsawan" dan "teater stambul" yang sudah ada saat itu. Menurut Firman Muntaco, seniman Betawi, Lenong berkembang dari proses teaterisasi musik Gambang Kromong, Kecrek, Kendang, Kempor, Suling, Gong serta alat musik khas Tionghoa misalnya Tehyan, Kongahyang, dan Sukong serta sebagai tontonan sudah dikenal sejak tahun 1920-an².

Cerita-cerita Lenong berkembang dari lawakan-lawakan tanpa alur cerita yang dirangkai-rangkai hingga menjadi pementasan semalam suntuk dengan lakon panjang dan utuh.

Pada mulanya kesenian ini dipertunjukkan dengan pementasan keliling dan berpindah-pindah dari kampung ke kampung. Pementasan digelar di alam terbuka tanpa panggunghanya beralaskan tanah tempat berpijak sebagai area panggung dengan properti seadanya juga kostum para pemeran alakadarnya. Tahun 1970-an baru dilakukan di atas panggung dengan properti sebuah meja dan dua sampai empat buah kursi juga latar Rumah Betawi yang dilukis (sebagai penanda/ikon teras rumah adat Betawi) dalam arsitektur betawi dinamakan 'Paseban'.

Ketika pertunjukan berlangsung, salah seorang pemeran pria atau wanita mengitari penonton sambil meminta sumbangan (kencleng) secara sukarela. Selanjutnya, Lenong mulai dipertunjukkan atas permintaan pelanggan dalam acara hajatan, seperti resepsi pernikahan dan sunatan. Setelah sempat mengalami masa sulit, pada tahun 1970an kesenian Lenong dimodifikasi dan mulai dipertunjukkan secara rutin di panggung Taman Ismail Marzuki Jakarta. Masuknya unsur teater modern dalam rangkaianserta tata panggungnya, durasi pementasan $L e-$ nong pun dipersingkat menjadi 2-3 jam saja, tidak lagi semalam suntuk. Selanjutnya, Lenong juga menjadi populer lewat pertunjukan melalui televisi, yaitu yang ditayangkan oleh Televisi Republik Indonesia mulai tahun 1970-an. Beberapa seniman Lenong yang menjadi terkenal sejak saat itu misalnya adalah H. Bokir, Nasir, Nori, Anen, Mandra, Omas dan masih banyak lagi.

Jenis Lenong Betawi, terdapat dua jenis Lenong yaitu 'Lenong Denes' dan 'Lenong Preman'. Bahasa yang digunakan dalam pentaspun, bukan bahasa Betawi sehari-hari, melainkan bahasa "Melayu Tinggi", dengan kata-kata ; "hamba", "kakanda", "adinda", "beliau", "daulat tuanku", "syahdan", berdatang sembah dan sebagainya. Bahasa demikian dewasa ini sudah sedikit sekali yang dapat menghayati, termasuk para seniman lenong sendiri. Oleh karenanya penggunaanya tampak kaku, sulit untuk dapat melahirkan humor spontan. Oleh karena itu pula makin menyusut peminatnya.

Lenong Denes biasa bermain di atas panggung, berukuran lebih $5 \times 7$ meter. Tempat seluas itu dibagi dua, sebagian untuk tempat pemain berhias, ganti pakaian, dudukduduk menunggu saat untuk tampil. Sebagian lagi digunakan sebagai pentas. Alat musik ditata panggung, sebelah kanan dan sebelah kiri pentas. Penggunaan dekor adalah untuk menyatakan susunan dalam adegan-adegan. Tetapi pada kenyataannya, penggunaannya sering tidak tepat, karena terbtasnya persediannya dekor atau kadangkadang karena kurang cermatnya pengatur dekor itu sendiri dalam menyesuaikan situasi, ruang dan waktu. Misalnya menurut cerita 


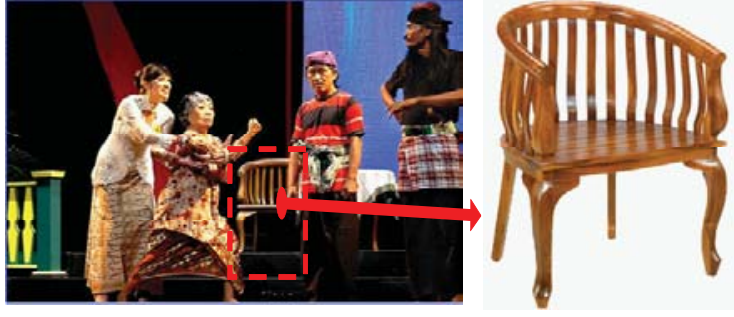

Gambar 6

Pementasan Lenong Betawi Preman dan Kostum Pelakon Jenis inFormal/ Keseharian dengan Properti Kursi Betawi Iga (Sumber: Google image, 4 Mei 2005)

sang puteri sedang bercengkrama di tamansari, disertai dayang-dayangnya, ternyata dekornya menggambarkan kota metropolitan dan gedung-gedung tinggi, mobil sedan berseliweran dijalan. Pakaian pentas sudah barang sedapat mungkin disesuaikan dengan lakon. Lenong Denes adalah adaptasi dari kisah-kisah cerita 1001malam.

Kisah yang dipentaskan dalam Lenong Preman misalnya kisah penindasan terhadap rakyat jelata oleh penguasa, kemudian muncullah tokoh pahlawan sebagai pembela rakyat melakukan perlawanan pada penguasa. Pada perkembangannya, Lenong Preman lebih populer dan berkembang dibandingkan Lenong Denes. Lenong Preman banyak menampilkan adegan laga atau action. Para permainan Lenong pun kebanyakan mahir bermain silat. Aliran silat yang umurnnya dikuasai pemain Lenong Preman adalah aliran silat Beksi. Semua pemain dapat berimprovisasi menampilkan humor, maka sepanjang pertunjukan Lenong Preman penuh dengan humor.

Dalam pementasannya digunakan panggung setinggi kurang lebih 1 meter dengan menggunakan dekor yang bergambar suasana perumahan dan pemandangan kota, Bahasa yang digunakan berdialek Betawi, pakaian yang dikenakan disesuaikan dengan jalan cerita. Tokoh biasanya digambarkan dengan memakai pakaian dan celana berpotongan koko dan pangsi, kaos oblong, dan ikat kepala (setangan).

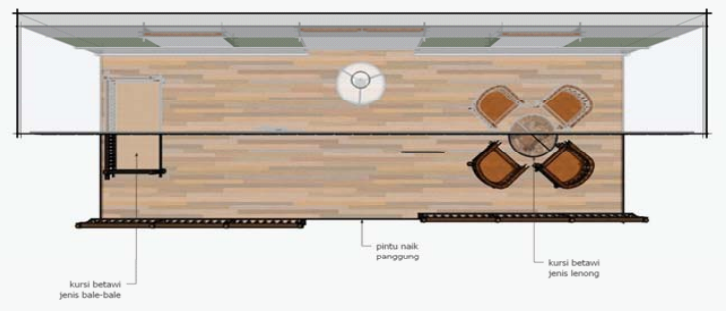

Gambar 7

Tampak Atas Peletakan Kursi Betawi pada Pementasan Lenong Betawi (Sumber: ilustrasi penulis)

Perbedaan dalam kedua jenis lenong ini terletak pada bahasa yang digunakan. Lenong denes menggunakan bahasa pengantar Melayu yang halus, sementara, lenong preman menggunakan bahasa informal percakapan sehari-hari. Pengisahan yang dilakukan dalam lenong preman juga merupakan kisah rakyat yang tertindas, yang mengundang kehadiran tokoh pendekar taat ibadah yang melawan kesemena-menaan tuan tanah. Intinya, penyebutan Denes dan Preman terletak pada bahasa yang digunakan dalam sebuah pementasan. Sederhananya, lenong denes diorientasikan pada kebudayaan kaum elit bangsa ini yang hidup dalam kemapaman. Sementara, lenong preman lebih pada aktualitas kehidupan masyarakat yang berada pada kebudayaan kalangan rakyat.

Penempatan set Kursi Betawi baik di rumah maupun di panggung pertunjukan selalu konsisten sama, yaitu di teras depan dengan latar belakang fasade atau tampak rumah tradisi Betawi, dengan jendela bukaan kiri dan kanan dari pintu utama berada di tengah fasade rumah. Penataan set latar belakang panggung pertunjukkan tersebut selalu dipilih karena menjadi suatu ke khasan dari masyarakat Betawi.

Berdasarkan bentuk dan fungsi Kursi Betawi tersebut dapat disaksikan bahwa ergonomi yang ada pada Kursi Betawi sangat mewakili perilaku dari masyarakat Betawi, ini tercermin dari bentuk, peletakkan set Kursi Betawi yang selalu di letakkan di area beranda atau lebih akrab di masyara- 
kat dengan sebutan teras tertutup depan rumah. Kaitan dengan kehidupan sosial, kursi betawi dengan bentuk $L e$ nong dengan dudukan kayu atau anyaman selalu diletakan di set depan, sedang-

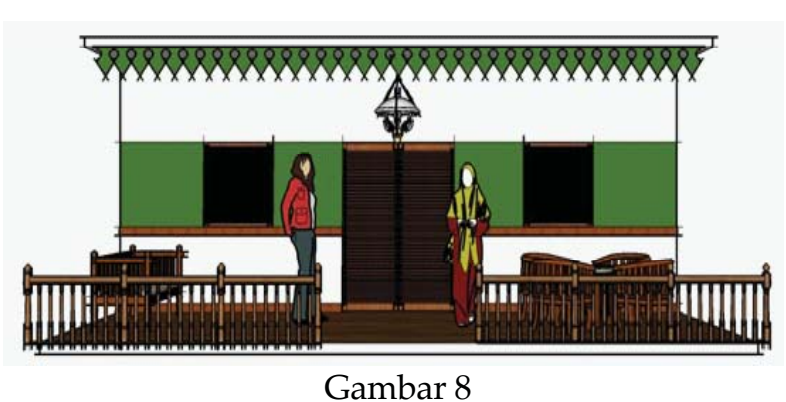

Ilustrasi Tampak Depan Panggung Lenong Betawi (Sumber: ilustrasi penulis) lingkar setengah lingkaran memiliki makna 'merangkul' siapapun yang duduk di kursi tersebut.Bentuksandaran setengah lingkaran sangat sesuai dengan punggung manusia, sehingga terasa nyaman bila diduduki. Ukuran dudukan kan model Kursi Betawi yang dikenal masyarakat Kursi Betawi Mobil-mobilan dan Kursi Betawi Bemo di set atau di letakan di dalam. Hal ini menunjukan hirarki dari tetamu siapa yang datang berkunjung berdasarkan tingkat ke akraban. Untuk tamu keluarga dan sudah tidak asing akan dipersilahkan masuk ke tengah rumah dan duduk di area duduk dengan set kursi yang lebih nyaman dan empuk dengan dudukan busa, yaitu Kursi Betawi Mobil-mobilan. Suguhannya pun selain kudapan juga bisa di persilahkan untuk makan bersama di area meja makan keluarga, karena peletakan serta set ruang duduk tersebut berdekatan dengan area makan keluarga.

Dari uraian tersebut di atas, dapat ditegaskan pula bahwa kursi Betawi merupakan representasi dari perkembangan aspek-aspek baru kehidupan sosial manusia serta perkembangan dalam pertujukanyang selalu dinamis. Hal-hal baru yang muncul dapat dimengerti dan berusaha diwujudkan dalam penataan set produksi tata panggung tradisi maupun modern. Lahirlah Kursi Betawi dilakukan pada beberapa elemen produksi kursi seperti pada material, struktur, ergonomi, finishing, dan proses produksi. Proses dan langkah-langkah ini merupakan perjalanan menuju perubahan menjadi standarisasi baru produksi kursi Betawi dengan mempertimbangkan berbagai aspek yaitu kebutuhan, fungsi dan penempatan, status sosial masyarakat, sertapelestarian keaslian bentukdan fungsi Kursi Betawi.

Bentuk sandaran Kursi Betawi yang me- yang cukup besar menambah kenyamanan untuk pengguna, karena bisa duduk sambil mengangkat kaki karena disesuaikan dengan perilaku masyarakat Betawi (yang agresif) pada masa penjajahan Portugis dan Belanda yang dikenal banyak para Jawara serta Pendekar pembela Tanah Betawi dari para penjajah.

\section{SIMPULAN}

Kursi Betawi sebagai properti seni pertunjukan 'Lenong Betawi' memiliki fungsi ganda, yakni memiliki fungsi praktis/pragmatis, dan fungsi estetik-simbolik. Fungsi praktis karena property tersebut memang dipergunakan sebagai tempat duduk pemain, sedangkan fungsi estetik-simbolik dari bentuk asli yang terbuat dari kayu dengan tekstur dan warna yang sangat merepresentasikan sebagai ikon budaya Betawi. Kursi betawi dalam seni pertunjukan tersebut mengangkat tema dan naskah dari budaya tradisi yang juga merepresentasikan makna simbolik status sosial dari keragaman jenis bentuk kursi yang ditampilkan.

Di sisi lain, konsep perancangan panggung pertujukan selalu bermula dari pemikiran untuk mengikuti naskah ataupun skrip yang dibuat oleh para penulis, bukan bertolak dari setting panggung. Dapat dikatakan bahwa setting panggung merupakan elemen pendukung dari naskah cerita yang selalu berubah mengikuti isu yang sedang ramai dibicarakan di masyarakat. Kursi dalam Lenong Betawi yang memiliki bentuk unik dan 
makna yang ternyata cukup dalam menjadi pelengkap serta properti dalam kebutuhan setting panggung. Pola bentuk pada kursi Betawi lebih mengarah ke nilai-nilai kebiasaan prilaku masyarakt Betawi pada zaman dahulu. Konsep kekinian yang dianutnya menggiring kursi Betawi masuk dalam khasanah estetika kontemporer, sementara di sisi lain konsep universal yang dikandungnya juga memasukkan Kursi Betawi ke dalam mazhab modernisme. Tanpa disadari selain peran fungsional, Kursi Betawi juga mempunyai peran lain, seperti point of interest, icon prototype, progressive Lenong representtation, serta aesthetic exposition.

Di zaman yang serba modern kini, untuk menikmati seni pertunjukkan seperti lenong tersebut diatas, sangatlah sulit karena kelangkaannya. Seiring dengan berbagai dinamika kemajuan zaman, melalui berbagai properti seni pertunjukan tersebut, peran kursi Betawi diharapkan dapat terus dipertahankan. Oleh karena itu, menjadi tanggung jawab bersama untuk terus melestarikan dan menjaga agar kebudayaan lokal ini tetap terpelihara. Apalagi, sebagai seorang generasi muda bangsa ini. Menjadi keniscayaan untuk tetap memelihara agar seni pertunjukkan yang sarat kebudayaan ini tetap dipertunjukkan di zaman modern. Memelihara kebudayaan bangsa adalah misi suci yang tak seharusnya padam. Sejatinya tetap menjunjung tinggi kebudayaan bangsa.

\section{Catatan kaki}

${ }^{1}$ Penjelasan secara detailnya dapat dilihat pada, Heru Subagiyo, "Tata Panggung Teater", Teater Lintang Songo, Wordpress diunduh Sabtu, 08 Agustus 2016) .

2Sumber: http://anggaputrar.blogspot.co.id/ 2013/04/kebudayaan-lenong-betawi.html).

\section{Daftar Pustaka}

Denzin, Norman K., and Yvonna S. Licoln

2009 Handbook Qualitative Research, Yogyayakarta: Penerbit Pustaka Pelajar

Gerry Rachmat

2005 Unsur-unsur Gaya Luar Terhadap Pembentukan Gaya Kursi Betawi, Thesis, FSRD ITB.

Gloag, John

1977 'A Short Dictionary of Furniture'. London: George Allen and Unwind

Sumber lain:

Heru Subagiyo, "Tata Panggung Teater" Wordpress Teater Lintang Songo, dalam https:// teaterku.wordpress.com/2010/03/24/tata panggung/di unduh diunduh Sabtu, 08 Agustus 2016)

http://anggaputrar.blogspot.co.id/2013/04/ kebudayaan-lenong-betawi.html 